\title{
Relationship of worksite smoking policy to changes in employee tobacco use: findings from COMMIT
}

\author{
Russell E Glasgow, K Michael Cummings, Andrew Hyland
}

\begin{abstract}
Objective-To report data on the impact of worksite smoking policies on employee smoking behaviour from a large and heterogeneous sample of smokers and worksites in 22 different communities across North America participating in the COMMIT trial.

Design and subjects-Data from a population-based survey of 8271 employed adult smokers who completed surveys in 1988 and 1993. Surveys included questions on tobacco use behaviours, personal/ demographic characteristics, and smoking policy and cessation resources at the workplace.

Results-After controlling for potential confounding factors, regression analyses revealed that employees who worked in a smoke-free worksite were over $25 \%$ more likely to make a serious quit attempt between 1988 and 1993, and over $25 \%$ more likely to achieve cessation than those who worked in a worksite that permitted smoking. Among continuing smokers, employees in smoke-free worksites consumed an average of $23 / 4$ fewer cigarettes per day compared with those who worked in places with a non-restrictive smoking policy. A smoke-free worksite policy was not associated with a greater likelihood of using smokeless tobacco.

Conclusion-These data, from one of the largest and longest smoking cessation studies to date, add support to the conclusion that smoke-free worksite policies help employees to reduce or discontinue use of tobacco.
\end{abstract}

(Tobacco Control 1997;6 (suppl 2):S44-S48)

Oregon Research Institute, Eugene, Oregon, USA RE Glasgow

Department of Cancer Control and

Epidemiology, Roswell Park Cancer Institute, Buffalo, New York $\mathrm{K}$ M Cummings A Hyland

Correspondence to: Dr K Michael Cummings, Department of Cancer Control and Epidemiology, Roswell Park Cancer Institute, Elm and Carlton Streets, Buffalo, New York 14263, USA; email:mcummings@ sc3102.med.buffalo.edu smoking policies on increasing the use of smokeless tobacco, although this relationship might be predicted from a compensatory tobacco use model. ${ }^{+}$

Few studies have investigated behaviour changes associated with worksite policies in the longer term, or had a sufficiently large sample size to comprehensively address potential confounding variables in multivariable analysis. One of the few exceptions is a recent study of the impact of California workplace smoking policies by Patten et al. ${ }^{7}$ This study found that workplace smoking policies may encourage changes in smoking behaviour.

We report data on changes in tobacco use behaviour and associated worksite smoking policies collected during the Community Intervention Trial for Smoking Cessation (COMMIT) ${ }^{8}{ }^{9}$ The COMMIT study followed a cohort of adult smokers for five years to document changes in tobacco use behaviours. Among those currently employed, information was collected on smoking policies at their workplace. The primary purpose of this study was to examine the relationship between workplace smoking restrictions and changes in the tobacco use behaviour of employed smokers. Specific goals were to examine the association of worksite smoking policies (collected in 1993 only) with: (a) quit attempts and rates of smoking cessation; (b) changes in consumption among continuing smokers; and (c) effects on smokeless tobacco use (among male baseline smokers).

\section{Methods}

The data analysed in this paper come from a longitudinal study involving 8271 cigarette smokers in 22 North American communities who were interviewed in 1988 and re-interviewed in 1993 as part of the COMMIT study. The overall trial design and primary outcomes have been described elsewhere. ${ }^{8-11}$ Briefly, the COMMIT study was a randomised, controlled trial conducted at the community level to test the effectiveness of a multifaceted intervention to help adult smokers achieve and maintain cessation. Intervention focused on four primary channels, including encouraging worksites to strengthen their smoking policies and to make cessation resources accessible to their employees. The study involved 11 matched pairs of communities: 10 pairs in the United States and one pair in Canada. 
DATA COLLECTION AND MEASURES

From January to May 1988 , a telephone survey was conducted to identify cohorts of heavy and light to moderate smokers within each of the following communities: Bellingham and Longview/Kelso, Washington; Albany/ Corvallis and Medford/Ashland, Oregon; Vallejo and Hayward, California; Santa Fe and Las Cruces, New Mexico; Cedar Rapids and Davenport, Iowa; Raleigh and Greensboro, North Carolina; Paterson and Trenton, New Jersey; Lowell and Fitchburg/Leominster, Massachusetts; Yonkers, New Rochelle, Utica, and Binghamton, New York; and Brantford and Peterboro, Ontario, Canada. The survey was conducted centrally using a modified, random-digit dialling technique and community-specific geographic screening to identify households within the targeted areas. The survey was implemented in two stages. The first stage involved identifying representative samples of approximately 5400 households within each community and gathering information on the age, gender, and smoking habits of all adults within selected households. In the second stage, approximately 550 light to moderate $(<25$ cigarettes per day) and 550 heavy ( $\geqslant 25$ cigarettes/day) smokers in each community aged 25-64 years were selected for an extended interview that included questions about current and past smoking habits, employment status, worksite smoking policy, and sociodemographic characteristics. Current smokers were defined as persons who reported having smoked at least 100 cigarettes in their lifetime and who reported smoking at the time of interview.

The mean response rate for the household rostering portion of the survey was $83.7 \%$. Of the eligible smokers identified from the household rostering, $91.5 \%$ completed the extended interview. The initial cohort identification survey gathered data on a total of 20347 smokers aged 25-64 years who were then followed prospectively until 1993. Between 1989 and 1992, cohort participants were contacted yearly by either telephone or mail to assess their current smoking status and residency. Between January and May 1993, cohort members were asked to respond to a 20-minute telephone interview, which included questions about current smoking and employment as well as their worksite smoking policy and any worksite smoking cessation services or resources.

Overall, $65.9 \%$ of cohort members $(n=$ $13415)$ provided information on their smoking status at the final contact in 1993. Most of the cohort members who were classified as non-respondents were those who could not be located $(29.8 \%, \mathrm{n}=6073)$; an additional $2.4 \% \quad(n=493)$ were reported deceased, and $1.5 \%(n=315)$ refused to participate in the follow-up survey. Attrition was higher for younger, single, less-educated members of the cohort. ${ }^{8}$ In addition, 5144 respondents who were not employed outside the home or did not know their worksite's smoking policy at the time of the follow-up interview ( $n=67$ ) were excluded, leaving 8271 subjects for the analysis.
WORKPLACE POLICY AND OTHER PREDICTOR VARIABLES

In the 1993 survey, respondents were asked if they were currently employed. Those that responded affirmatively were asked which of the following best described their worksite smoking policy: prohibited everywhere; allowed in designated areas only; or allowed everywhere. Workers were also asked if their worksite has distributed smoking cessation materials or offered smoking cessation programmes, contests, or lotteries in the last five years. Other predictor variables obtained from the baseline interview in 1988 include age, race, income, education, amount smoked, quit attempts in the year before 1988 , desire to quit, and COMMIT intervention status.

\section{OUTCOME MEASURES}

Outcomes variables measured from the 1993 follow-up interview were quit attempts between 1988 and 1993, smoking status and amount smoked in 1993, and, for men, use of smokeless tobacco in 1993. A respondent is considered to have made a quit attempt between 1988 and 1993 if he/she indicated they had made a serious quit attempt during the follow-up period or if he/she is classified as a successful quitter in 1993. A quitter is defined as a cohort member who reported not smoking in the six months preceding the follow-up interview. Amount smoked is the average number of cigarettes smoked per day in 1993. A respondent is considered to use smokeless tobacco if he/she self-reported using smokeless tobacco regularly.

\section{ANALYSES}

Bivariate associations among the dependent variables and reported worksite smoking policies and cessation resources were examined using the $\chi^{2}$ test. Standard logistic and multiple regression models were constructed to examine the role of the worksite's smoking policy while controlling for potential confounder variables (age, race, education, income, amount smoked, desire to quit, past quit attempts, and worksite cessation services and resources). These analyses were performed using SPSS. ${ }^{12}$ To account for the clustered nature of the COMMIT data, the same models were also performed using SUDAAN. ${ }^{13}$ Parameter standard errors obtained from SUDAAN are inflated to the extent that the responses from within a given community are correlated, hence, this approach yields more conservative results. However, the results from SUDAAN models were the same as those obtained using SPSS. As most people are familiar with SPSS, we have chosen to present only the results obtained using SPSS. The SUDAAN results are available from the authors.

\section{Results}

DESCRIPTIVE STATISTICS

As can be seen in table 1, the employed smokers in this cohort were a heterogeneous group of smokers. As would be expected given the selection procedures, the mean baseline 
Table 1 Participant baseline characteristics: employed smokers in COWMIT surveys

\begin{tabular}{|c|c|c|}
\hline \multirow[b]{2}{*}{ Employee/worksite characteristics } & \multicolumn{2}{|c|}{ Employed smokers } \\
\hline & $n$ & $\%$ \\
\hline \multicolumn{3}{|l|}{ Sex } \\
\hline Male & 4360 & 52.7 \\
\hline Female & 3911 & 47.3 \\
\hline \multicolumn{3}{|l|}{ Race } \\
\hline White & 6243 & 75.5 \\
\hline Black & 515 & 6.2 \\
\hline Asian & 89 & 1.1 \\
\hline American Indian & 65 & 0.8 \\
\hline Canadian & 918 & 11.1 \\
\hline Hispanic & 410 & 5.0 \\
\hline Other & 24 & 0.3 \\
\hline \multicolumn{3}{|l|}{ Age (years) } \\
\hline $25-34$ & 3058 & 37.0 \\
\hline $35-44$ & 3043 & 36.8 \\
\hline $45-54$ & 1682 & 20.3 \\
\hline $55-64$ & 488 & 5.9 \\
\hline \multicolumn{3}{|l|}{ Education (years) } \\
\hline$<12$ & 1193 & 14.5 \\
\hline 12 & 1864 & 22.6 \\
\hline $13-15$ & 3566 & 43.2 \\
\hline$\geqslant 16$ & 1633 & 19.8 \\
\hline \multicolumn{3}{|l|}{ Gross income (US\$) } \\
\hline$<10000$ & 429 & 5.5 \\
\hline $10000-25000$ & 2261 & 29.0 \\
\hline 2500140000 & 2719 & 34.9 \\
\hline$>40000$ & 2380 & 30.6 \\
\hline \multicolumn{3}{|l|}{ Cigarettes smoked daily in 1988} \\
\hline$<5$ & 430 & 5.2 \\
\hline $5-14$ & 1520 & 18.4 \\
\hline $15-24$ & 2946 & 35.6 \\
\hline $25-34$ & 2102 & 25.4 \\
\hline$\geqslant 35$ & 1266 & 15.3 \\
\hline \multicolumn{3}{|l|}{ Desire to quit } \\
\hline None & 1258 & 15.3 \\
\hline A little & 1285 & 15.6 \\
\hline Somewhat & 2765 & 33.6 \\
\hline A lot & 2922 & 35.5 \\
\hline \multicolumn{3}{|l|}{ Past quit attempts } \\
\hline 0 & 5108 & 61.9 \\
\hline 1 & 1571 & 19.0 \\
\hline$\geqslant 2$ & 1577 & 19.1 \\
\hline \multicolumn{3}{|l|}{ COMMIT } \\
\hline Intervention & 4139 & 50.0 \\
\hline Comparison & 4132 & 50.0 \\
\hline
\end{tabular}

smoking rate was relatively high ( 22.8 per day, SD 12.1), and more than $40 \%$ of the sample smoked 25 or more cigarettes per day.

By 1993, 28\% of the respondents reported that their worksite prohibited any indoor smoking; 54\% reported that their employer permitted smoking only in designated areas, and $18 \%$ said that smoking was allowed everywhere in their worksite. A third of the employees reported that their worksite had distributed smoking cessation materials and $26 \%$ said that their employer had offered smoking cessation programmes at work during the past five years. Nineteen per cent of respondents reported their worksite offered both a programme on site and cessation materials.

Between 1988 and 1993, 72\% of baseline smokers made a quit attempt, and $31 \%$ of these reported having quit for at least six months at the time of the follow-up assessment $(23 \%$ quit rate overall). Of continuing smokers, $66 \%$ reported decreasing consumption between 1988 and 1993, whereas $21 \%$ reported an increase and $13 \%$ smoked at the same level.

BIVARIATE RELATIONS BETWEEN SMOKING POLICY AND EMPLOIEE OUTCOMES

As table 2 shows, there was a significant relationship between smoking policy stringency and employee quit attempts, probability of cessation, and reduction in amount smoked (among continuing smokers), but not smokeless tobacco use (among men). More stringent smoking policies were associated with higher rates of quit attempts, greater likelihood of quitting, reduction in number of cigarettes smoked, and, contrary to what some would expect, lowered rates of smokeless tobacco use.

MULTIPLE LOGISTIC REGRESSIONS

The above bivariate relationships, although informative, could also be due to confounding between various "third variables" such as different employee characteristics. A series of multiple logistic regressions were conducted, therefore, to control for these potential confounding variables. All of the variables listed in table 1 were entered along with smoking policy. This analysis removes effects due to the set of remaining variables when evaluating the significance of the odds ratio for each variable.

The results of these analyses are summarised in table 3. As can be seen, after controlling for the significant effects of gender, race, education, amount smoked, and provision of cessation resources and programmes at the worksite, smoking policy stringency was independently and positively associated with quit attempts, quit rates, and reduction in amount smoked. It is interesting that a ban seems to be required to impact quit rates, whereas a policy designating smoking areas shows a reduction in number of cigarettes smoked, compared with policies that do not restrict smoking.

\section{Discussion}

This study had three goals. The first was to determine if more stringent smoking policies were associated with increased probability of quit attempts and successful quitting among employees experiencing these policies. The answer to this question was clearly yes, from both bivariate and multivariable analyses. The second question was whether, among

Table 2 Bivariate relations between worksite smoking policy and employee smoking behaviour

\begin{tabular}{|c|c|c|c|c|}
\hline \multirow[b]{2}{*}{ Outcome } & \multirow[b]{2}{*}{${ }_{n}^{\text {Sample size }}$} & \multicolumn{3}{|c|}{ Worksite policy } \\
\hline & & $\begin{array}{l}\text { Smoking allowed } \\
(\%)\end{array}$ & $\begin{array}{l}\text { Designated areas } \\
(\%)\end{array}$ & $\begin{array}{l}\text { Smoke-free policy } \\
(\%)\end{array}$ \\
\hline $\begin{array}{l}\text { Quit attempt from } 1988 \text { to } 1993(\%) \\
\text { Quit from } 1988 \text { to } 1993(\%) \\
\text { Average daily cigarette consumption in } 1993^{\star} \\
\text { Use smokeless tobacco in } 1993(\%) \dagger\end{array}$ & $\begin{array}{l}8271 \\
8271 \\
5725 \\
4358\end{array}$ & $\begin{array}{r}66.9 \\
20.0 \\
24.1 \\
2.6\end{array}$ & $\begin{array}{r}71.9 \\
21.0 \\
20.8 \\
2.8\end{array}$ & $\begin{array}{r}75.1 \\
26.9 \\
18.4 \\
2.0\end{array}$ \\
\hline
\end{tabular}

* Among those employees who continued to smoke in 1993.

tAmong male employees (smokeless use among females was negligible). 

Table 3 Resulss from multiple linear (MR) and multiple logistic regressions (LR) to predict changes in employee smoking
behaviour: relative risk estimates or beta weights and significance

\begin{tabular}{|c|c|c|c|c|}
\hline \multirow[b]{2}{*}{ Predictor variable } & \multicolumn{4}{|c|}{ Outcome variables } \\
\hline & $\begin{array}{l}\text { Smoking quit } \\
\text { attempt } \\
\text { (LR) }\end{array}$ & $\begin{array}{l}\text { Quit smoking } \\
\text { (LR) }\end{array}$ & $\begin{array}{l}\text { Amount smoked in } \\
1993 \\
\text { (MR) }\end{array}$ & $\begin{array}{l}\text { Smokeless tobacco uset } \\
(L R)\end{array}$ \\
\hline \multicolumn{5}{|l|}{$\begin{array}{l}\text { Sex } \\
\text { Male }\end{array}$} \\
\hline $\begin{array}{l}\text { Male } \\
\text { Female }\end{array}$ & Referent & Referent & Referent & NA \\
\hline \multicolumn{4}{|l|}{$\begin{array}{l}\text { Race } \\
\text { White }\end{array}$} & \\
\hline White & Referent & Referent & Referent & Referent \\
\hline Black & 0.85 & 0.97 & -0.95 & 0.00 \\
\hline Asian & 0.80 & 0.69 & -0.57 & 0.45 \\
\hline American Indian & 0.96 & 1.11 & 1.20 & 0.00 \\
\hline Other & 1.46 & 1.31 & 0.85 & 3.57 \\
\hline Canadian & 1.09 & 0.91 & -0.65 & 0.51 \\
\hline $\begin{array}{r}\text { Hispanic } \\
\text { Age (years) }\end{array}$ & 0.87 & 1.00 & $-1.71^{\star}$ & 0.59 \\
\hline \multicolumn{5}{|l|}{$\begin{array}{l}\text { Age (years) } \\
25-34\end{array}$} \\
\hline $\begin{array}{l}25-34 \\
35-44\end{array}$ & 0.91 & $\begin{array}{l}\text { Referent } \\
1.03\end{array}$ & Referent & Referent \\
\hline $\begin{array}{l}35-44 \\
45-54\end{array}$ & $0.80^{\star}$ & $\begin{array}{l}1.03 \\
1.13\end{array}$ & 0.15 & 0.88 \\
\hline $\begin{array}{l}43-34 \\
55-64\end{array}$ & 0.80 & $\begin{array}{l}1.13 \\
1.36^{\star}\end{array}$ & -0.65 & 0.77 \\
\hline \multicolumn{5}{|l|}{ Education (years) } \\
\hline$<12$ & Referent & Referent & Referent & Referent \\
\hline 12 & 0.99 & $1.23^{*}$ & -0.47 & 1.81 \\
\hline $13-15$ & 0.95 & 1.12 & $-0.96^{\star}$ & 1.26 \\
\hline & 0.96 & 1.17 & \multirow{2}{*}{\multicolumn{2}{|c|}{$\begin{array}{l}\text { Gross income (US\$) } \\
<10000\end{array}$}} \\
\hline $\begin{array}{l}\text { Gross income (US\$) } \\
<10000\end{array}$ & Referent & Referent & & \\
\hline $10000-25000$ & 0.81 & 1.01 & $\begin{array}{l}\text { Kererent } \\
-0.71\end{array}$ & $\begin{array}{l}\text { Referent } \\
0.86\end{array}$ \\
\hline $25001-40000$ & 0.93 & 1.13 & -0.78 & 0.83 \\
\hline \multirow{2}{*}{\multicolumn{5}{|c|}{$\underset{<5}{\text { Cigarettes smoked daily in } 1988}$}} \\
\hline & & & & Referent \\
\hline $5-14$ & $0.66^{\star}$ & $0.62^{\star}$ & & \\
\hline $15-24$ & $0.57^{\star}$ & $0.34^{\star}$ & & 0.47 \\
\hline $25-34$ & $0.54^{\star}$ & $0.29^{\star}$ & & $0.39^{\star}$ \\
\hline \multicolumn{5}{|l|}{ Desire to quit in 1988} \\
\hline None & Referent & Referent & Referent & Referent \\
\hline A little & $1.30^{\star}$ & & -0.41 & 0.94 \\
\hline $\begin{array}{l}\text { Somewhat } \\
\text { A lot }\end{array}$ & $1.97^{\star}$ & 1.12 & -0.63 & 1.06 \\
\hline \multicolumn{5}{|l|}{ Past quit attempts } \\
\hline 0 & Referent & Referent & Referent & Referent \\
\hline 1 & $2.73^{\star}$ & 1.10 & -0.30 & \\
\hline \multicolumn{5}{|l|}{ Worksite smoking policy } \\
\hline Allowed everywhere & Referent & Referent & Referent & \\
\hline Designated areas & $1.16^{\star}$ & 1.00 & $-1.17^{\star}$ & 1.23 \\
\hline \multirow{2}{*}{\multicolumn{3}{|c|}{ Worksite services and resources }} & & 0.91 \\
\hline & Referent & & & \\
\hline Offer services or materials & $1.34^{\star}$ & 0.99 & 0.21 & $\begin{array}{l}\text { Referent } \\
0.86\end{array}$ \\
\hline \multicolumn{5}{|l|}{ COMMIT status } \\
\hline Comparison & Referent & Referent & Referent & Referent \\
\hline Intervention & 1.07 & 1.08 & -0.42 & 0.86 \\
\hline
\end{tabular}

For male employees only.

$\star \mathrm{P}<0.05$.

$\mathrm{NA}=$ not applicable.

continuing smokers, more stringent policies were associated with reduced consumptionfor example, fewer total cigarettes per day. This was also answered affirmatively.

Because of concern that smokers might "compensate" by increasing use of smokeless/ spitting tobacco when faced with a worksite smoking ban, we specifically addressed this issue also. The results indicate a nonsignificant reduction in the use of smokeless/ spitting tobacco among employees at smoke-free workplaces, rather than an increase. Thus, it appears that worksite smoking restrictions are not associated with increases in smokeless/spitting tobacco use.

This investigation has both methodological strengths and limitations. The large number and heterogeneity of employees and worksites studied throughout North America is an important strength, as is the long timeframe of the study. The multivariate analyses and control for potential confounding factors, and for intraclass correlations via SUDAAN, also lend confidence to the conclusions above. On the negative side, we did rely on self-reports of changes in smoking behaviour. We feel justified in this, given that both COMMIT data ${ }^{89}$ and other large-scale community-based studies have shown that rates of falsely reporting abstinence in such community intervention and non-demand assessment conditions are low, and do not show treatment vs control condition biases. ${ }^{14} 15$

Another potential weakness is that, unlike the study by Patten et $a l^{7}$ the design was not prospective in nature, as smoking policy information was collected only in 1993. It is possible that employees who were studied switched worksites between 1988 and 1993 to avoid smoking bans. However, this scenario seems unlikely as other studies have failed to find evidence that smokers quit working at a 
location because of restrictions on smoking. ${ }^{16} 17$ Unfortunately, in this study it was not possible to determine whether those who quit smoking did so before or after a smoke-free policy was established. Therefore, we cannot directly examine the effect of banning smoking at the worksite on the cigarette smoking behaviour of employees. A final consideration is that we measured employee perception of their worksite's smoking policy rather than the actual policy. Some might argue that this, however, is a strength rather than a weakness, as other studies have documented discrepancies between what a written policy says and how it is actually implemented. ${ }^{18}$

Our findings, when considered with results from other large-scale studies of worksite smoking restrictions, ${ }^{17}$ may explain why the tobacco industry fights so hard to oppose clean indoor air laws. Smoking restrictions in the worksite result in less tobacco consumption, which means fewer cigarettes sold and lower profits for cigarette companies. Based on the results of this study, we estimate that if all worksites in the United States were to implement a smoke-free policy, an additional 178000 smokers would stop smoking and, among those who continued to smoke, they would consume 10 billion fewer cigarettes per year.

The financial implications of a smoke-free worksite policy may help explain why cigarette manufacturers have invested heavily in developing new products that attempt to reduce secondhand smoke. For example, RJ Reynolds recently introduced a new cigarettelike product (Eclipse) that heats rather than burns tobacco thereby reducing secondhand smoke. Eclipse seems to be intended for smokers concerned about secondhand smoke. In Sweden, RJ Reynolds is marketing this "reduced smoke" product under the name "Inside". 19

In summary, together with recent evidence from California ${ }^{20}$ and other studies, ${ }^{1420}$ these findings argue for the benefit of smoke-free worksite policies for smokers, as well as the more direct effects of reducing environmental tobacco smoke exposure. ${ }^{321}$ Future prospective studies are recommended to further investigate the long-term impact of worksite smoking bans and cessation resource combinations, and to see if these programmes have greater effects on some smokers than othersfor example, heavy $v$ s light smokers).
Support for this research has been provided by the National Cancer Institute and the Robert Wood Johnson Foundation. W' are indebted to our colleagues at the 11 COMMIT research sites, the COMMIT coordinating centre, Information Management Services, Inc., and staff at the National Cancer Institute who planned and coordinated the massive data collection activities of the COMMIT study.

1 Borland R, Pierce JP, Burns DM, Gilpin E, Johnson M, Ba $D$. Protection from environmental tobacco smoke in California. The case for a smoke-free workplace. $\mathcal{J} A M A 1992$ 268:749-52.

2 Rigotti NA. Trends in the adoption of smoking restrictions in public places and worksites. $N Y \mathcal{F}$ Med 1989;89:19-26.

3 Hammond SK, Sorensen G, Youngstrom R, Ockene JK Occupational exposure to environmental tobacco smoke. ЭAMA 1995;274:956-60.

4 Borland R, Chapman S, Owen N, Hill D. Effects of workplace smoking bans on cigarette consumption. Am $\mathcal{F}$
Public Health 1990;80:178-81.

5 Emont SL, Choi WS, Novotny TE, Giovino GA. Clean indoor air legislation, taxation, and smoking behaviour in the United States: an ecological analysis. Tobacco Control 1992;2:13-17.

6 Mullooly JP, Schuman KL, Stevens VJ, Glasgow RE, Vogt TM. Smoking behavior and attitudes of employees of a large HMO before and after a work site ban on cigarette smoking. Public Health Rep 1990;105:623-8.

7 Patten CA, Gilpin E, Cavin SW, Pierce JP. Workplace smoking policy and changes in smoking behaviour in California a suggested association. Tobacco Control 1995;4:36-41.

8 COMMIT Research Group. Community Intervention Trial for Smoking Cessation (COMMIT): I. Cohort results from a four-year community intervention. Am f Public Health 1995;85:183-92.

9 COMMIT Research Group. Community Intervention Trial for Smoking Cessation (COMMIT): II. Changes in adult cigarette smoking prevalence. Am $\mathcal{F}$ Public Health 1995; 85:193-200.

10 COMMIT Research Group. Community Intervention Trial for Smoking Cessation (COMMIT): summary of design and intervention. $\mathcal{F}$ Natl Cancer Inst 1991;83:1620-8.

11 Mattson ME, Cummings KM, Lynn WR, et al. Evaluation plan for the Community Intervention Trial for Smoking pessation (COMMIT). Int $Q$ Commun Health Educ 1990; 11:271-90.

12 Norusis MJ. SPSS for Windows: advanced statistics, release 6.0. SPSS, 1993.

13 Shah BV, Barnell BG, Hunt PN, LaVange LM. SUDAAN user's manual: professional software for survey data analysis for multi-stage sample designs, release 6.0. Triangle Park, North Carolina: Research Triangle Institute, 1992.

14 Glasgow RE, Mullooly JP, Vogt TM, et al. Biochemical validation of smoking status in public health settings: pros, cons, and data from four low-intensity intervention trials. Addict Behav 1993;18:511-27. 15 Velicer WF, Prochaska JO, Rossi JS, Snow MG. Assessing
outcome in smoking cessation studies. Psychol Bull 1992;111:23-41.

16 Becker RN, Conner HF, Waranch, HR, et al. The impact of a total ban on smoking in the John's Hopkins Children's Center. $\mathcal{F A M A}$ 1989;262:799-802.

17 Hurt $\mathrm{RD}$, Berge KG, Offord $\mathrm{KP}$, et al. The making of a smoke-free medical center. $\mathscr{F} A M A$ 1989;261:95-7.

18 Rigotti NA, Pashos CL. No-smoking laws in the United States: an analysis of state and city actions to limit smoking in public places and workplaces. $¥ A M A 1991 ; 266: 3162-7$.

19 Glantz SA. Changes in cigarette consumption, prices, and tobacco industry revenues associated with California's tobacco industry revenues associated with
Proposition 99. Tobacco Control 1993;2:311-4.

20 Carol J, Burns D. Environmental tobacco smoke. In: Tobacco use: an American crisis. Final conference report and recommendations from America's health community. Washington, DC: American Medical Association, 1993.

21 Pierce J, Farkas A, Evans N, et al. Tobacco use in California: a focus on preventing uptake in adolescents. Sacramento: California Department of Health Services, 1993. 